\title{
COMMUNITY-ASSOCIATED METHICILLIN-RESISTANT STAPHYLOCOCCUS AUREUS ST8 ("USA300") IN AN HIV- positive patient in Cologne, Germany, February 2008
}

W Witte (wittew@rki.de) ${ }^{1}$, C Braulke ${ }^{1}$, B Strommenger ${ }^{1}$

1. Robert Koch Institut, Wernigerode, Germany
The first cases of community-associated methicillin-resistant Staphylococcus aureus (CA-MRSA) were reported in 1996 in Minnesota, United States (US) and were deep-seated skin and soft tissue infections and a few cases of necrotising pneumonia, mainly in children and among the Native American population [1]. A few years later, a large outbreak of CA-MRSA infections was reported in the men who have sex with men (MSM) community in California, predominantly among human immunodeficiency virus (HIV)-positive patients; data on sexual transmission was not available [2]. A recent report on the spread of CA-MRSA, mainly due to the widely disseminated strain "USA300", in numerous MSM in San Francisco and in one patient in Boston suggested sexual transmission [3], but initiated critical reviews concerning the transmission route and the corresponding public health message $[4,5]$.

CA-MRSA "USA300", the most widely spread CA-MRSA strain in the US [6], has been detected in Germany since 2005 [7]. This clonal lineage is characterised by multilocus sequence type (MLST) ST8, spa-sequence type t008, SCCmec IVa, the presence of an additional arginine decomposition pathway (arginine catabolic mobile element (ACME) on a staphylococcal cassette chromosome (SCC)-element) with arcA as marker gene, and macrolide-resistance coded by the msrA (efflux pump) and mphB (phosphorylation) genes $[7,8]$. The contribution of ACME to virulence has been shown in a rabbit model [9]. The capacity of CA-MRSA "USA300" to cause invasive infections seems not to be due to production of the Panton-Valentine leukocidin cytotoxin, but rather to the synthesis of a large number of small phenol-soluble peptides, which are able to recruit and lyse neutrophilic granulocytes [10].

Here we report a case of infection with CA-MRSA ST8 ("USA300") in an HIV-positive 35-year-old MSM patient in Cologne, Germany. The isolate originated from an infected cyst in the upper abdominal area, which opened spontaneously. The patient suffered from acquired immunodeficiency syndrome (AIDS). His CD4+ T-cell count was $200 /$ microlitre with a fully suppressed virus load due to HIV treatment. A specimen from the cyst was taken for microbiological diagnostics. Primary topical treatment was performed by instillation of Leukase beads containing trypsin, framycetin sulphate and lidocaine hydrochloride (Merck, Vienna). After obtaining the microbiology results, oral doxycyclin $(200 \mathrm{mg}$ per day) was included in the treatment. The infection had healed completely after 14 days. Nasal swabs were negative for MRSA.
The isolate exhibited the typical characteristics of CA-MRSA ST8 ("USA300", see above). It was resistant to oxacillin, erythromycin, ciprofloxacin, moxifloxacin and susceptible to gentamicin, oxytetracycline, clindamycin, rifampicin, cotrimoxazole, fusidic acid, linezolid, fosfomycin, tigecycline and daptomycin.

As shown in the US, CA-MRSA ST8 ("USA300") may spread rapidly in MSM communities [3]. European doctors caring for HIVpositive patients and MSM with skin and soft tissue infections should be aware of the possibility of CA-MRSA in order to provide proper care and prevent further spread.

Targeted measures include proper bacteriological diagnosis of skin and soft tissue infections in patients attending dermatological and surgical practises, as well as in HIV-positive patients. When MRSA is detected, it is likely that the infection is caused by a CA-MRSA strain. Early recognition of CA-MRSA ST8 ("USA300") is possible by PCR detection of the lukS-lukF and arcA genes [11]. Confirmation is obtained by additional typing such as spatyping, MLST, and SCCmec [7]. Further spread can be prevented by personal, environmental and health care hygienic measures $[12,13]$.

\section{References}

1. Naimi TS, LeDell KH, Boxrud DJ, Groom AV, Steward CD, Johnson SK, et al. Epidemiology and clonality of community-acquired methicillin-resistant Staphylococcus aureus in Minnesota. Clin Infect Dis. 2001 Oct 1;33(7):990-6.

2. Centers for Disease Control and Prevention (CDC). Outbreaks of communityassociated methicillin-resistant Staphylococcus aureus skin infection - Los Angeles County California, 2002-2003. MMWR Morb Mortal Wkly Rep. 2003;52(5):88. Available from: http://www.cdc.gov/mmwr/preview/mmwrhtml/ mm5205a4.htm

3. Diep BA, Chambers HF, Graber $C J$, Szumowski JD, Miller $L G$, Han $L$, et al. Emergence of multidrug-resistant, community-associated, methicillinresistant Staphylococcus aureus clone USA300 in men who have sex with men. Ann Intern Med. 2008;148(4):249-57.

4. Skiest D, Brown K, Cooper TW, Hoffman-Roberts H, Mussa HR, Elliott AC. Prospective comparison of methicillin-susceptible and methicillin-resistant community associated Staphylococcus aureus infections in hospitalized patients. J Infect. 2007;54(5):427-34.

5. Centers for Disease Control and Prevention (CDC). CDC statement on MRSA in men who have sex with men. 2008 Jan 16. Available from: http://www.cdc.gov/ od/oc/media/pressrel/2008/t080116.htm 
6. Van de Laar MJW, Monnet DL, Herida M. Multidrug-resistant methicillinresistant Staphylococcus aureus (MRSA) strain in a men-who-have-sex-withmen (MSM) community in the United States: comment. Euro Surveill. 2008;13(3). Available from: http://www.eurosurveillance.org/edition/v13n03/080117_1. asp

7. Witte W, Strommenger B, Cuny C, Heuck D, Nuebel U. Methicillin-resistant Staphylococcus aureus containing the Panton-Valentine leucocidin gene in Germany in 2005 and 2006. J Antimicrob Chemother. 2007;60(6):1258-63.

8. Tenover F, McDougal L, Goering RV, Killgore G, Projan SJ, Patel JB, et al. Characterization of a strain of community-associated methicillin-resistant Staphylococcus aureus widely disseminated in the United States. J Clin Microbiol. 2006;44(1):108-18.

9. Chambers HF. Deconstructing virulence of the community MRSA clone USA300. in NARSA 8th Annual Meeting. 2007. Reston, VA, USA, March 5-6. Available from: http://www3.niaid.nih.gov/topics/antimicrobialResistance/PDF/ futureMedicineMRSAeditorial.pdf

10. Wang R, Braughton KR, Kretschmer D, Bach TH, Queck SY, Li M, et al. Identification of novel cytolytic peptides as key virulence determinants. Nature Med. 2007;13(12):1510-4.

11. Strommenger B, Braulke C, Pasemann B, Schmidt C, Witte W. Multiplex PCR for rapid detection of Staphylococcus aureus isolates suspected to represent community-acquired strains. J Clin Microbiol. 2008;46(2):582-7.

12. Cohen PR. Community-acquired methicillin-resistant Staphylococcus aureus skin infections: implications for patients and practitioners. Am J Clin Dermatol. 2007;8(5):259-70.

13. Wiese-Posselt M, Heuck D, Draeger A, Mielke M, Witte W, Ammon A et al. Successful termination of a furunculosis outbreak due to lukS-lukF-positive, methicillin-susceptible Staphylococcus aureus in a German village by stringent decolonization, 2002 - 2005. Clin Infect Dis. 2007:44(11):88-95.

This article was published on 27 March 2008.

Citation style for this article: Witte W, Braulke C, Strommenger B. Community-associated methicillin-resistant Staphylococcus aureus ST8 ("USA300") in an HIV-positive patient in Cologne, Germany, February 2008. Euro Surveill. 2008;13(13):pii=8080. Available in Cologne, Germany, February 2008. Euro Surveill. 2008;13(13):pii=8080.
online: http://www.eurosurveillance.org/ViewArticle.aspx?ArticleId $=8080$ 